\title{
In memoriam Christian Müller
}

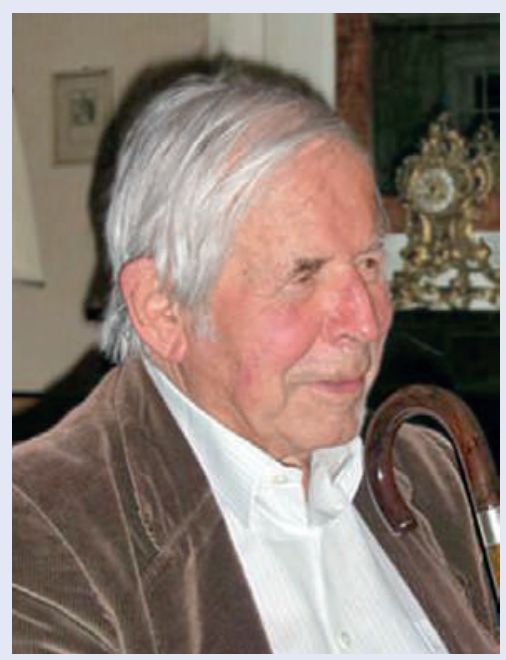

Prof. Dr. med. Christian Müller (11.8.1921-29.3.2013)

Am Karfreitag verstarb in Bern der ehemalige Direktor der Psychiatrischen Universitätsklinik Lausanne Christian Müller. Zuvor hatte er bei voll erhaltener geistiger Präsenz seine Mobilitätsbeeinträchtigung würdig erduldet.

Professor Müller war ein weit über die Landesgrenzen hinaus anerkannter Pionier der schweizerischen Psychiatrie. Unzählige Kolleginnen und Kollegen im In- und Ausland erinnern sich dankbar an einen wahren Patron, der sie mit seinem Beispiel im menschlichen und sozialen Engagement für die Verbesserung der Situation von psychisch Leidenden unterstützt und durch seine Kultiviertheit und produktive publizistische Kreativität sehr beeindruckt hat.

Christian Müller verbrachte seine Kindheitsjahre in der Psychiatrischen Klinik Münsingen, als sie von seinem Vater Max Müller (später Ordinarius an der Universität Bern und Direktor der Universitätsklinik Waldau) geleitet wurde und wegen der dort angewandten Insulintherapie ein internationales Zentrum war. Als Oberarzt an der Zürcher Universitätsklinik Burghölzli bei Manfred Bleuler erlangte er durch die Publikation einer erfolgreichen Psychotherapie eines an chronischer Schizophrenie leidenden Kranken bereits grosses Ansehen in der psychoanalytischen Fachwelt, das er als Lehranalytiker zeitlebens beibehielt. Aus einer mit Gaetano Benedetti gegründeten Arbeitsgruppe entstand später die heute noch aktive ISPS International Society for Psychotherapy of Schizophrenia.
Während seines 25-jährigen Ordinariates an der Universität Lausanne von 1961-1986 ist es ihm zusammen mit Luc Ciompi, dem späteren Ordinarius für Sozialpsychiatrie in Bern, in der «Enquête de Lausanne» gelungen, durch Untersuchungen von Jahrzehnteverläufen bei gravierenden Störungen wie der Schizophrenie langfristige Heilungschancen nachzuweisen.

Eine weitere Pionierleistung war die 1962 erfolgte Eröffnung einer später von Jean Wertheimer geführten psychogeriatrischen Spezialklinik und die Publikation des ersten Lehrbuches zur Alterspsychiatrie 1967. Müllers Aufgeschlossenheit für innovative Verfahren zeigte sich auch in der systemischen Therapie mit dem Pionier Luc Kaufmann, der bereits Anfang der 70er Jahre in der Lausanner Klinik familientherapeutisch arbeitete. Daneben setzte sich Müller für die therapeutische Nutzung von Film, Malerei und Musik sowie die soziale und berufliche Wiedereingliederung von Langzeitpatienten ein. Auch der Psychopharmakologie räumte er mit Pierre Baumann die ihr gebührenden Entwicklungsmöglichkeiten ein. In der Waadt setzte er sich hauptsächlich für eine moderne, sektorisierte, gemeindenahe Psychiatrieversorgung nach französischem Vorbild ein. 1976 als Ordinarius an die Psychiatrische Universitätspoliklinik nach Bern berufen, kündigte er bereits nach einer Woche wieder und kehrte nach Lausanne zurück, weil die Regierung nicht wie versprochen auf seine Vorschläge zur Dezentralisierung der Psychiatrie eintrat.

Dieser Eklat war u. a. Anstoss zum Grossratsbeschluss vom 15.11.1977 zur Psychiatriereform im Kanton Bern, mit dem die «Psychiatriestützpunkte», also dezentrale psychiatrische Dienste auf der Basis der regionalen Allgemeinspitäler, ins Leben gerufen wurden. Es freute Christian Müller besonders, dass es mit dem Unterzeichnenden einem seiner Schüler vergönnt war, einen solchen gemeindenahen regionalen Dienst in seinem Sinne aufbauen zu dürfen. In Müllers gastfreundlicher und herzlicher Umgebung entwickelte sich daraus eine langjährige Freundschaft.

Christian Müller hat Historisches in der Psychiatrie bewirkt, nach der Emeritierung selber psychiatriegeschichtlich geforscht sowie meisterhaft Geschichten und Anekdoten zur Psychiatrie geschrieben und erzählt. Nun sind sein Mut, seine Ausstrahlung, sein Schalk und seine Empathie selber Geschichte.

Dr. med. Werner Saameli, ehem. Chefarzt Psychiatrische Dienste Thun 